\title{
Adherence to hormone therapy among women with breast cancer
}

\author{
Claudia Brito ${ }^{1 *}$, Margareth Crisóstomo Portela ${ }^{1}$ and Mauricio Teixeira Leite de Vasconcellos ${ }^{2}$
}

\begin{abstract}
Background: Despite the excellent results obtained with hormone therapy, the long treatment period and the side effects associated with its use make patient adherence difficult. Moreover, certain aspects of health care can mitigate or exacerbate non-adherence. This study aimed to identify the factors associated with adherence to hormone therapy for breast cancer, with the goal of contributing to the reformulation of the care process and to improvements in outcomes.

Method: This was a retrospective longitudinal study based on secondary data. The study integrated and analyzed data from a cohort of 5,861 women with breast cancer who were identified in the databases of the Brazilian National Cancer Institute [Instituto Nacional de Câncer - INCA] and the Unified Health System [Sistema Único de Saúde - SUS]. All of the patients were treated at INCA, which dispenses free medication, and the follow-up period lasted from 01/01/2004 to 10/29/2010. The outcome of interest was hormone treatment adherence, which was defined as the possession of medication, and a logistic regression model was employed to identify the socio-demographic, behavioral, clinical, and health care variables that were independently associated with the variations in this outcome.

Results: The proportion of women who adhered to hormone therapy was $76.3 \%$. The likelihood of adherence to hormone therapy increased with each additional year of age, as well as among women with a secondary or higher level education, those with a partner, those who underwent surgery, those who had more consultations with a breast specialist and clinical oncologist, and those who underwent psychotherapy; the effect for the latter increased with each additional consultation. Conversely, the likelihood of adherence was lower among patients at a non-curable stage, those who were alcohol drinkers, those who received chemotherapy, those who had undergone more tests and had more hospitalizations, and those who used tamoxifen and combined aromatase inhibitors.
\end{abstract}

Conclusion: This study shows that approximately a quarter of the women with breast cancer did not adhere to hormone treatment, thus risking clinical responses below the expected standards. It also identifies the most vulnerable subgroups in the treatment process and the aspects of care that provide better results.

Keywords: Breast cancer, Adherence, Hormone therapy, Tamoxifen, Aromatase inhibitors, Organization of care, Risk factors, Health care organization, Quality of health care

\section{Background}

Studies of endocrine therapy for breast cancer treatment have been increasingly performed throughout the world [1] due to the large patient volume [2], the long treatment duration [3], the optimal obtained results [4,5], and the adverse drug effects [6,7].

\footnotetext{
* Correspondence: cbrito@ensp.fiocruz.br

'Department of Health Administration and Planning of National School of Public Health Sergio Arouca, Oswaldo Cruz Foundation, Av. Leopoldo Bulhões, 1480/ Sala 717 -Manguinhos, 21041-210 Rio de Janeiro, RJ, Brazil Full list of author information is available at the end of the article
}

Adjuvant endocrine therapy or hormone therapy for breast cancer involves the use of hormone suppressants or similar substances to inhibit tumor growth [7]. This type of therapy is associated with lower rates of disease recurrence and metastasis and, thus, improves mortality rates and disease-free survival $[4,8]$. Consequently, its use and related expenses have increased significantly in recent decades [2].

The duration of hormone treatment is relatively long, and patients are required to use the medication daily for 5 years [3] to obtain the maximum benefits [9]. The increase in oral medication use has highlighted a potential

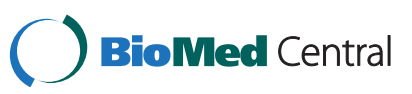


problem in the adherence to cancer treatment in both health and economic terms. If patients do not take their medications, they will not benefit from them, thus resulting in increased mortality and morbidity as well as increased costs and consumption of care resources. Moreover, if the doctor is unaware of the patient's nonadherence to oral therapy, he/she might attribute the disease progression to the ineffectiveness of the drug and change the regimen unnecessarily [10] or prescribe a second- or third-line medicine with greater side effects or costs. In Brazil, breast cancer is the leading cause of cancer deaths among women (12,852 deaths in 2010), and it is estimated that in 2013, 52,680 women will be diagnosed with this type of tumor [11].

Despite the excellent results obtained with hormone therapy, the long treatment period and the side effects associated with its use make patient adherence difficult, which can lead to adverse clinical outcomes [12,13]. Moreover, certain aspects of health care (e.g., the doctor-patient relationship and the management of side effects) can mitigate or exacerbate non-adherence $[1,8]$, even for patients with a good prognosis $[14,15]$.

This study aimed to identify the factors associated with adherence to hormone therapy for breast cancer, with the goal of contributing to the reformulation of the care process and to improved outcomes.

\section{Methods}

A hospital-based population retrospective longitudinal study was conducted with secondary data from women with breast cancer who received hormone therapy prescriptions from the National Cancer Institute (Instituto Nacional de Câncer; INCA) of Brazil.

INCA is the Ministry of Health reference center for cancer policies and care [16] and as such, INCA integrates the public health system and provides all inpatient and outpatient oncological treatment modalities free of charge. It is also the largest breast cancer care provider in the state of Rio de Janeiro, which has the highest incidence of this disease in Brazil [11].

The study included all women with breast cancer who appeared in the hospital-based cancer registry (hospitalbased cancer registry; RHC) between 2002 and 2008 who started hormone treatment with tamoxifen (TMX) and/or the aromatase inhibitors (AIS) letrozole or anastrozole on or after $01 / 01 / 2004$, and who received dispensed medication more than once before 10/29/2010, according to the INCA pharmacy (the only medicine dispensary for those women).

An integration and analysis of the information found in the following databases was performed as follows:

a. The dispensing database from the INCA pharmacy aggregated data about medicine dispensation, including the date, type (TMX, letrozole and anastrozole) and quantity. It permitted the acquisition and delivery control of medicine with satisfactory accuracy. Only patients who started hormone therapy after 01/01/2004 were considered because this database was established in October 2003 and thus included patients who required continuous treatment. The last included dispensing date was 10/29/2010.

b. The RHC database was implemented at INCA according to the recommendations of the International Agency for Research on Cancer (IARC) and was employed in the study to obtain sociodemographic and clinical variables.

The study inclusion criteria for women with breast cancer tumors who were enrolled between 2002 and 2008 relied on data availability at the time of the study. The RHC was organized by tumor, which meant that a single patient with more than 1 primary malignant tumor (excluding recurrence or metastasis) could be registered more than once. For patients with multiple recorded tumors, we used the more complete observation, the observation with the highest stage if the diagnosis dates were the same or the earliest observation if the diagnosis dates were different.

c. The Integrated Hospital System (Sistema Hospitalar Integrado; SHI) and the INCA Absolute System databases were used to record the procedures provided to women with breast cancer. The SHI was established in 1998 and was used at INCA until 2004, at which time it was replaced by the Absolute system. We evaluated data from $01 / 01 / 2002$ to 10/29/2010. The Absolute system had more data categories than the SHI and thus required data cleaning to make the records compatible. The option for the use of both SHI and Absolute as sources of health care variables relied on their comprehensiveness; this was in contrast to RHC, which only included data concerning chemotherapy, radiotherapy, and oncological surgery.

After combining the databases, the differences in dates between the beginning of hormone treatment and the diagnosis of breast cancer were calculated. There were 198 cases with negative values; these were most likely due to typographical errors, and the data were subsequently corrected according to the following procedures. (1) If the initial hormone treatment date was $\leq 3$ months earlier than the date of diagnosis, the diagnosis and the initiation of hormone treatment were assumed to coincide (i.e., the difference was equal to 0). (2) If the negative difference between the start of hormone therapy and the diagnosis was $>3$ months, and if the second 
medication dispensing date was consistent with the diagnosis date, the first dispensing date was ignored and replaced with the second date, and the amount dispensed on the discarded date was deducted from the total. With these procedures, it was possible to retain 185 cases in the analysis; however, 13 women were eliminated due to a complete lack of consistency in the data.

Thus, data for 5,861 women were retained for analysis in the integrated database. There was no systematic association between the excluded cases and the variables of interest; thus, there is a low probability that data exclusion due to operational issues might have introduced bias into the study.

Adherence is defined as the extent to which a patient acts in accordance with the prescribed interval and dose of a dosing regimen, and is operationalized, in a retrospective assessment, as the number of doses dispensed in relation to the dispensing period, often called the "medication possession ratio (MPR)" [12,17-19].

It was calculated, for each woman, by summing up all quantities dispensed, and dividing the sum by her time in the cohort, that, in turn, was given by the difference between the last and the first dispensing date summed to the last dispensed quantity, for those that did not die, and between the death and the first dispensing date, for those that died [12,17-19]. We considered the recommendation of a daily hormone therapy (HT) pill for five years. The drugs that INCA dispensed free of charge were TMX and AIS.

Patients with an MPR $\geq 80 \%$ were considered adherent, which is a criterion widely applied [20-22].

The independent variables of interest included sociodemographic variables (RHC) such as the age at diagnosis, education, and marital status; clinical variables (RHC) such as the histological tumor type, stage, laterality, family history of cancer, smoking, and alcohol consumption; and treatment and health care variables (SHI/Absolute). The latter included the type of hormone therapy (e.g., TMX only, AIS only, letrozole or anastrozole, or both TMX and AIS, which indicated a switch from one form of therapy to the other), surgery, chemotherapy (CT), radiation therapy (RT), hospitalizations, clinical consultations with mastologists, clinical oncologists and other doctors, psychotherapy, multi-professional therapeutic support (MTS) (including nursing ambulatory care, nutrition services, physical therapy, speech therapy and psychology), services from a social worker, dentist or pharmacist, diagnostic and therapeutic services (DTS), and the time between the diagnosis and the initiation of hormone treatment.

Bivariate analyses of adherence were conducted with the chi-squared $\left(x^{2}\right)$ test for categorical independent variables and Student's t-test for continuous variables. Multivariate logistic regression was also used, while excluding variables without independent effects $(p \geq 0.15)$ for parsimoniousness. The analyses were performed with the $\mathrm{SAS}^{\bullet}$ statistical software package, version 9.1 (SAS Institute Inc., 2003; Cary, NC, USA).

The study was approved by the Research Ethics Committee of INCA under number 84/2010.

\section{Results}

The patient age at diagnosis ranged from 21 to 103 years, with a mean of $57.5(\mathrm{SD}=13.6)$ years and a median of 56.6 years. Approximately $50 \%$ of the women were between 40 and 59 years old, and only a minority was younger than 40 years. Half of the women in the cohort had a low level of education (e.g., they were illiterate or had an incomplete elementary education), and 10\% had completed a higher education level.

The adherence rate was compiled from the information for each time frame as follows:

The mean and median follow-up periods were 1225 $(\mathrm{SD}=631)$ and 1209 days, respectively. The cohort showed a mean and median adherence of $86.3 \%$ and $94.3 \%$, respectively. If the patients with at least $80 \%$ adherence to treatment were assumed to be adherent, the proportion of adherent patients was $76.3 \%$.

The group of adherent women was slightly older than the group of non-adherent women, with mean ages of 58.0 and 56.0 years, respectively (student's t-test, $\mathrm{p}<0.0001$ ). Based on the chi-square test, we found associations of adherence with all categorical variables except the histological primary tumor type $(\mathrm{p}=0.6049)$ and laterality ( $\mathrm{p}=0.2690$; Tables 1, 2 and 3).

Table 1 presents the results according to sociodemographic variables and shows the lower likelihood of adherence among younger women ( $<40$ years). Table 1 also shows the higher likelihood of adherence among women who had completed second grade or higher and among those with a partner; these factors were found to have borderline associations.

In relation to the clinical variables (Table 2), the results show a higher likelihood of adherence among women with a family history of cancer and a lower likelihood of adherence among women who were alcohol drinkers or smokers. The likelihood of adherence was especially low among those who were diagnosed with cancer at a noncurable stage (III and IV).

With regard to the variables related to patient care (Table 3), there was a higher likelihood of adherence in women who were treated with TMX alone, as well as those who underwent surgery. In contrast, women who were treated with both types of hormone therapy (switching from 1 form of therapy to the other), who underwent radiotherapy, who had more consultations with clinical oncologists, or who underwent seven or more chemotherapy procedures, hospitalizations, and tests all had a lower likelihood of adherence. The results also revealed a lower 
Table 1 Distribution of socio-demographic characteristics according to adherence to hormone treatment $(\mathrm{N}=\mathbf{5 , 8 6 1 )}$

\begin{tabular}{|c|c|c|c|c|c|}
\hline \multirow[t]{2}{*}{ Variable } & \multicolumn{2}{|c|}{ Adherent } & \multicolumn{2}{|c|}{ Non-adherent } & \multirow[t]{2}{*}{$x^{2}(p)$} \\
\hline & $\mathbf{N}$ & $\%$ & $\mathrm{~N}$ & $\%$ & \\
\hline Age (years) & & & & & $<0.0001$ \\
\hline$<40$ & 342 & 65.9 & 177 & 34.1 & \\
\hline $40-49$ & 1,052 & 74.4 & 362 & 25.6 & \\
\hline $50-59$ & 1,165 & 77.7 & 334 & 22.3 & \\
\hline $60-69$ & 950 & 79.0 & 253 & 21.0 & \\
\hline$>70$ & 961 & 78.4 & 265 & 21.6 & \\
\hline Education & & & & & 0.0530 \\
\hline Illiterate + incomplete 1st grade & 2,219 & 75.4 & 724 & 24.6 & \\
\hline Complete 1st grade & 772 & 74.8 & 260 & 25.2 & \\
\hline 2nd grade + higher education & 1,444 & 78.5 & 395 & 21.5 & \\
\hline No information & 35 & 74.5 & 12 & 25.5 & \\
\hline $\begin{array}{l}\text { Relationship status at start } \\
\text { of treatment }\end{array}$ & & & & & 0.0022 \\
\hline With a partner & 2,135 & 78.3 & 590 & 21.6 & \\
\hline Without a partner & 2,307 & 74.5 & 791 & 25.5 & \\
\hline No information & 28 & 73.7 & 10 & 26.3 & \\
\hline
\end{tabular}

frequency of adherence among women who had not consulted with a mastologist and among those who had not received professional therapeutic support or psychotherapy.

Table 4 shows the multiple logistic regression model that identified the effects of the explanatory variables on adherence to hormone therapy.

The likelihood of adherence increased with increasing age $(\mathrm{OR}=1.012,95 \% \mathrm{CI}=1.006-1.018)$ and with the number of psychotherapy consultations ( $\mathrm{OR}=1.055,95 \%$ $\mathrm{CI}=1.025-1.086)$. It was greater among women with a mid-level education $(\mathrm{OR}=1.248,95 \% \mathrm{CI}=1.055-1.477)$ or higher education $(\mathrm{OR}=1.362,95 \% \mathrm{CI}=1.07-1.722)$, as well as among those with a partner $(\mathrm{OR}=1.264,95 \%$ $\mathrm{CI}=1.106-1.444)$, those who underwent breast cancer surgery $(\mathrm{OR}=1.281,95 \% \mathrm{CI}=1.120-1.466)$, those who consulted with a mastologist (1-4 visits, OR $=1.524,95 \%$ $\mathrm{CI}=1.220-1.904 ; \quad \geq 5$ visits, $\mathrm{OR}=3.598,95 \% \mathrm{CI}=2.911$ 4.447 ) or an oncologist ( $1-4$ visits, $\mathrm{OR}=1.277,95 \% \mathrm{CI}=$ $1.052-1.550 ; \geq 5$ visits, $\mathrm{OR}=1.378 ; 95 \% \mathrm{CI}=1.142-1.662$ ), and those who underwent one or no exams (OR $=1.291$, $95 \% \mathrm{CI}=1.107-1.507)$. On the other hand, the likelihood of adherence was lower among patients diagnosed at a noncurable stage $(\mathrm{OR}=0.481,95 \% \mathrm{CI}=0.418-0.552)$, those who were alcohol drinkers $(\mathrm{OR}=0.797,95 \% \mathrm{CI}=0.690$ $0.921)$, those who received chemotherapy $(\mathrm{OR}=0.764$; 95\% CI $=0.651-0.897)$, those who had three or more hospitalizations $(\mathrm{OR}=0.587,95 \% \mathrm{CI}=0.498-0.693)$ or at least
Table 2 Distribution of clinical characteristics according to adherence to hormone treatment $(N=5,861)$

\begin{tabular}{|c|c|c|c|c|c|}
\hline \multirow[t]{2}{*}{ Variable } & \multicolumn{2}{|c|}{ Adherent } & \multicolumn{2}{|c|}{ Non-adherent } & \multirow[t]{2}{*}{$x^{2}(p)$} \\
\hline & $\mathbf{N}$ & $\%$ & $\mathrm{~N}$ & $\%$ & \\
\hline Family history of cancer & & & & & 0.0454 \\
\hline Yes & 2,519 & 77.5 & 732 & 22.5 & \\
\hline No & 1,816 & 74.9 & 610 & 25.1 & \\
\hline No information & 135 & 73.4 & 49 & 26.6 & \\
\hline Alcohol consumption & & & & & 0.0082 \\
\hline Yes & 1,181 & 73.6 & 424 & 26.4 & \\
\hline No & 3,164 & 77.4 & 924 & 22.6 & \\
\hline No information & 125 & 74.4 & 43 & 25.4 & \\
\hline Smoker & & & & & 0.0014 \\
\hline Yes & 1,503 & 73.9 & 530 & 26.1 & \\
\hline No & 2,902 & 77.7 & 832 & 22.3 & \\
\hline No information & 65 & 69.1 & 29 & 30.8 & \\
\hline $\begin{array}{l}\text { Histological type of } \\
\text { primary tumor }\end{array}$ & & & & & 0.6049 \\
\hline Invasive ductal carcinoma (IDC) & 3,561 & 76.1 & 1117 & 23.9 & \\
\hline Other tumors & 909 & 76.8 & 274 & 23.2 & \\
\hline Laterality & & & & & 0.2690 \\
\hline Unilateral & 4,293 & 76.4 & 1325 & 23.6 & \\
\hline Bilateral & 173 & 73.3 & 63 & 26.7 & \\
\hline No information & 4 & 57.1 & 3 & 42.8 & \\
\hline Stage & & & & & $<0.0001$ \\
\hline Curable & 2,742 & 83.4 & 544 & 16.6 & \\
\hline Non-curable & 1,549 & 65.3 & 822 & 34.7 & \\
\hline No information & 179 & 87.7 & 25 & 12.2 & \\
\hline
\end{tabular}

four exams $(\mathrm{OR}=0.720,95 \% \mathrm{CI}=0.596-0.871)$, and those who were treated with both TMX and AIS (OR $=0.730$, 95\% CI $=0.630-0.846)$.

\section{Discussion}

The observed level of adherence to hormone therapy (76.3\%) in this study was consistent with those found in other published studies, that indicated, considering the same criteria to define adherence, proportions of $75 \%$ [20] and $72 \%$ [22], or a mean adherence of 93\% [12]. However, we underline the difficulties of correlating some available previous studies due to differences in adherence definitions, eligibility criteria (e.g., patients with early tumors or only either young or elderly women), analysis methods, and the types of drugs used (only TMX, only IAS, or both).

The method employed in this study, as in others, accounts for medication delivery as a proxy for medication use, what may result in an overestimation of adherence rates. It is a limitation, but it is believed that the bias 
Table 3 Distribution of breast cancer treatment procedures according to adherence to hormone treatment $(\mathrm{N}=5,861)$

\begin{tabular}{|c|c|c|c|c|c|}
\hline \multirow[t]{2}{*}{ Variable } & \multicolumn{2}{|c|}{ Adherent } & \multicolumn{2}{|c|}{ Non-adherent } & \multirow[t]{2}{*}{$x^{2}(p)$} \\
\hline & $\mathrm{N}$ & $\%$ & $\mathbf{N}$ & $\%$ & \\
\hline Type of hormone therapy & & & & & $<0.0001$ \\
\hline TMX only & 3,014 & 79.8 & 762 & 20.2 & \\
\hline AIS only & 256 & 75.5 & 83 & 24.5 & \\
\hline Both (TMX + AIS) & 1,200 & 68.7 & 546 & 31.3 & \\
\hline Surgery & & & & & 0.0007 \\
\hline Yes & 2,720 & 77.8 & 775 & 22.2 & \\
\hline No & 1,750 & 74.0 & 616 & 26.0 & \\
\hline Chemotherapy & & & & & $<0.0001$ \\
\hline Yes & 2,553 & 72.3 & 978 & 27.7 & \\
\hline No & 1,917 & 82.3 & 413 & 17.7 & \\
\hline Radiotherapy & & & & & $<0.0001$ \\
\hline Yes & 2,036 & 73.4 & 736 & 26.5 & \\
\hline No & 2,434 & 78.8 & 655 & 21.2 & \\
\hline Therapeutic combination & & & & & $<0.0001$ \\
\hline HT only & 447 & 80.9 & 105 & 19.0 & \\
\hline HT and surgery & 762 & 84.8 & 137 & 15.2 & \\
\hline $\mathrm{HT}$ and $\mathrm{CT}$ & 395 & 68.2 & 184 & 31.8 & \\
\hline HT and RT & 405 & 80.5 & 98 & 19.5 & \\
\hline $\mathrm{HT}, \mathrm{CT}$ and surgery & 830 & 78.4 & 229 & 21.6 & \\
\hline HT, RT and surgery & 303 & 80.6 & 73 & 19.4 & \\
\hline $\mathrm{HT}, \mathrm{CT}$ and $\mathrm{RT}$ & 503 & 68.7 & 229 & 31.3 & \\
\hline$H T, C T, R T$ and surgery & 825 & 71.1 & 336 & 28.9 & \\
\hline CT frequency & & & & & $<0.0001$ \\
\hline No procedure & 1,917 & 82.3 & 413 & 17.7 & \\
\hline 1 to 3 procedures & 560 & 81.2 & 130 & 18.8 & \\
\hline 4 to 6 procedures & 1,463 & 82.3 & 314 & 17.7 & \\
\hline$\geq 7$ procedures & 530 & 49.8 & 534 & 50.2 & \\
\hline Frequency of hospitalization & & & & & $<0.0001$ \\
\hline None & 752 & 78.2 & 209 & 21.7 & \\
\hline One & 2,250 & 80.5 & 544 & 19.5 & \\
\hline Two & 909 & 76.9 & 273 & 23.1 & \\
\hline$\geq 3$ & 559 & 60.5 & 365 & 39.5 & \\
\hline Mastologist consultations & & & & & $<0.0001$ \\
\hline None & 343 & 55.6 & 274 & 44.4 & \\
\hline 1 to 4 consultations & 693 & 69.2 & 308 & 30.8 & \\
\hline 5 to 13 consultations & 2,473 & 83.2 & 498 & 16.8 & \\
\hline$\geq 14$ consultations & 961 & 75.5 & 311 & 24.5 & \\
\hline Clinical oncologist consultatio & & & & & $<0.0001$ \\
\hline None & 1,006 & 80.3 & 251 & 20.0 & \\
\hline 1 to 4 consultations & 1,325 & 79.1 & 349 & 20.8 & \\
\hline 5 to 12 consultations & 1,126 & 74.6 & 384 & 25.4 & \\
\hline
\end{tabular}

Table 3 Distribution of breast cancer treatment procedures according to adherence to hormone treatment $(\mathrm{N}=\mathbf{5 , 8 6 1 )}$ (Continued)

\begin{tabular}{lrrrrl}
\hline$\geq 13$ consultations & 1,013 & 71.3 & 407 & 28.7 & \\
Other physician consultations & & & & & $<.0001$ \\
$\leq 9$ consultations & 410 & 67.9 & 194 & 32.1 & \\
10 to 22 consultations & 1,683 & 78.0 & 475 & 22.0 & \\
23 to 34 consultations & 1,316 & 80.5 & 319 & 19.5 & \\
$\geq 35$ consultations & 1,061 & 72.5 & 403 & 27.5 & \\
Psychotherapy consultations & & & & & $<0.0001$ \\
None & 2,422 & 72.7 & 909 & 27.3 & \\
1 to 3 consultations & 1,577 & 80.0 & 394 & 20.0 & \\
$\geq 4$ consultations & 471 & 84.3 & 88 & 15.7 & \\
Therapeutic support consultations & & & & $<0.0001$ \\
None & 994 & 70.8 & 410 & 29.2 & \\
1 to 3 consultations & 1,553 & 77.3 & 457 & 22.7 & \\
4 to 7 consultations & 872 & 77.2 & 258 & 22.8 & \\
$\geq 8$ consultations & 1,051 & 79.8 & 266 & 20.2 & \\
DATS (tests) & & & & & $<0.0001$ \\
None & 870 & 78.2 & 242 & 21.8 & \\
1 test & 1,587 & 79.1 & 420 & 20.9 & \\
2 to 3 tests & 1,377 & 75.8 & 439 & 24.2 & \\
$\geq 4$ tests & 636 & 68.7 & 290 & 31.3 & \\
\hline
\end{tabular}

can be attenuated when estimations are made on the basis of secondary data from large populations [23].

Another limit of this study was the absence of individual information regarding treatment side effects, which could certainly affect hormone therapy adherence [24].

The truncation of adherence in cases where it reached levels above $100 \%$ is justified by the awareness of situations such as the occurrence of deaths, change of medication, and anticipated drug deliveries to meet patient needs.

Only women who received drugs at least twice were included in the study, once the MPR formula requires two dispensing dates. This procedure could have contributed to over or underestimations of the adherence rates, since who received the medication only one time could have been adherent or not to treatment in another place.

Moreover, we underline the difference between the concepts of treatment adherence and persistence, indicating that adherent patients may be non-persistent if they interrupt the treatment before the recommended period of five years.

This study was based on data from a single hospital, and we acknowledge that this might be a limitation. Nevertheless, it is important to emphasize that the hospital allows universal access, restricting entrance only to patients who was treated previously in other locations. 
Table 4 Multiple logistic regression model for adherence to hormone treatment $(N=5,861)$

\begin{tabular}{|c|c|c|c|c|c|}
\hline Variable & Coefficient & Standard error & $\operatorname{Pr}>x^{2}$ & Odds ratio & $95 \% \mathrm{Cl}$ \\
\hline Intercept & -0.3642 & 0.2591 & 0.1598 & & \\
\hline Age $^{*}$ (years) & 0.0117 & 0.0029 & $<0.0001$ & 1.012 & $1.006-1.018$ \\
\hline \multicolumn{6}{|l|}{ Education } \\
\hline High school diploma & 0.2216 & 0.0858 & 0.0098 & 1.248 & $1.055-1.477$ \\
\hline Bachelor's degree & 0.3087 & 0.1197 & 0.0099 & 1.362 & $1.077-1.722$ \\
\hline Conjugal status - with a partner & 0.2341 & 0.0681 & 0.0006 & 1.264 & $1.106-1.444$ \\
\hline Disease stage - non-curable & -0.7329 & 0.0711 & $<0.0001$ & 0.481 & $0.418-0.552$ \\
\hline Alcohol consumption (yes) & -0.2266 & 0.0735 & 0.0020 & 0.797 & $0.690-0.921$ \\
\hline Breast cancer surgery (yes) & 0.2478 & 0.0686 & 0.0003 & 1.281 & $1.120-1.466$ \\
\hline Chemotherapy (yes) & -0.2686 & 0.0816 & 0.0010 & 0.764 & $0.651-0.897$ \\
\hline Hospitalizations ( $\geq 3$ ) & -0.5322 & 0.0842 & $<0.0001$ & 0.587 & $0.498-0.693$ \\
\hline \multicolumn{6}{|l|}{ Mastologist visits } \\
\hline $1-4$ & 0.4215 & 0.1135 & 0.0002 & 1.524 & $1.220-1.904$ \\
\hline$\geq 5$ & 1.2805 & 0.1081 & $<0.0001$ & 3.598 & $2.911-4.447$ \\
\hline \multicolumn{6}{|l|}{ Oncologist visits } \\
\hline $1-4$ & 0.2446 & 0.0989 & 0.0134 & 1.277 & $1.052-1.550$ \\
\hline$\geq 5$ & 0.3203 & 0.0958 & 0.0008 & 1.378 & $1.142-1.662$ \\
\hline \multicolumn{6}{|l|}{ Diagnostic and therapeutic services } \\
\hline$\leq 1$ exam & 0.2557 & 0.0788 & 0.0012 & 1.291 & $1.107-1.507$ \\
\hline$\geq 4$ exams & -0.3284 & 0.0968 & 0.0007 & 0.720 & $0.596-0.871$ \\
\hline Psychotherapy ${ }^{*}$ (consultations) & 0.0534 & 0.0147 & 0.0003 & 1.055 & $1.025-1.086$ \\
\hline Type of hormone therapy - both (TMX + AIS) & -0.3148 & 0.0751 & $<0.0001$ & 0.730 & $0.630-0.846$ \\
\hline
\end{tabular}

$\mathrm{Cl}=$ Confidence interval. * Continuous variables. References for categorical variables: education - incomplete high school or lower, no information; conjugal status at start of treatment - without a partner, no information; disease stage - curable, no information; alcohol consumption - no, no information; breast cancer surgery - no; chemotherapy - no; hospitalization - <3; mastologist consultations - none; clinical oncologist consultations - none; DTS - 2-3 exams; type of hormone therapy - TMX only, AIS only.

The observed association between adherence and age in this study agrees with some studies $[12,19,21,25]$ yet contradicting others [26]. It can be speculated that the observed lower adherence rate among younger patients is related to the adverse effects of hormone therapy on the women's sexuality, which include fertility issues and menopausal symptoms [13]. Moreover, the association of greater treatment compliance with having a partner, also found in other studies [22,26], might be linked to support reception. This result is consistent with the idea that social support is highly predictive of adherence [1].

In this cohort, there was greater adherence among women with higher education levels, contrasting to findings of Wigertz et al. [26], who did not identify a statistically significant association between adherence and education. Anyway, it must be noted that it is very difficult to ensure that education in the Brazilian context is comparable to that of developed countries, and there are few other national studies on the subject. It is plausible the observation of greater adherence among patients with higher education while considering, among other things, that socioeconomic status has also been identified as predictive of adherence [21].

With regard to the disease stage, the observation of lower compliance among patients at non-curable stages (III and IV) contradicts Wigertz et al. [26], who found greater adherence among women with larger tumors. Kimmick et al. [20] found no association between these variables. Importantly, however, the majority of studies on this topic were based only on cohorts of women with early stage disease, which reflects the reality in developed countries, wherein $60 \%$ of tumors are diagnosed at a localized stage and thus women who are fighting the disease are at a great advantage.

In Brazil, despite the efforts of the Ministry of Health to implement national policies for earlier breast cancer detection, the proportion of advanced-stage diagnoses is very high, compared to that in developed countries [27]. The lower adherence rates among women with a noncurable stage at diagnosis emphasize the importance of investments in early diagnosis since it has a direct effect on patient survival $[4,8]$ and also an indirect effect by facilitating treatment compliance. 
Bivariate analyses conducted in this study identified the association between both smoking and alcohol consumption and lower treatment adherence [21], while the multivariate analysis ratified only the effect of alcohol consumption on the dependent variable.

This study reinforces the importance of surgery in breast cancer treatment. Previously, surgery had been associated with longer survival $[27,28]$, and herein, it was associated with greater patient adherence to hormone therapy. The current study also revealed that patient monitoring by mastologists and oncologists had a positive association effect on hormone therapy adherence [19]. However, a more intensive use of health care resources such as chemotherapy, exams and hospitalizations appeared to associate with lower adherence. This result was not directly observed in other studies but may be indirectly related to the association between lower adherence and comorbidities, observed in other studies $[15,20]$. Additionally, it should be emphasized that the independent effects of these clinical variables, even after controlling for the disease stage at diagnosis, might reflect the different levels of tumor aggressiveness, different levels of treatment responses, and the presence of comorbidities.

Another notable finding in this study was the independent positive effect of psychotherapy consultations on the likelihood of treatment adherence. This result might be related to those of studies that related psychological problems, particularly depression, to lower treatment adherence [1].

For Kim \& Toge [29], a multidisciplinary approach to breast cancer treatment broke down barriers to access, facilitated cooperation between doctors to produce better treatment proposals, and improved the quality of care and patient satisfaction. Although the multidisciplinary team approach to oncology is required by the Brazilian Ministry of Health [16] and is a necessary condition to hospital certification for the provision of oncological care in the Unified Health System (Sistema Único de Saúde; SUS), the present study indicates that between $24.0 \%$ and $57.0 \%$ of women who were treated at INCA had no records of multidisciplinary therapeutic support consultations or psychotherapy, respectively. Thus, more consultations with nurses, psychologists, social workers and physiotherapists should be encouraged in the clinical monitoring phase. Steps that facilitate the patient's understanding of the need for treatment and that promote and monitor adherence should be valued. Multidisciplinary therapeutic support consultations were associated with greater adherence to hormone therapy in the bivariate analysis, but were not significant in the multivariate model when psychotherapy consultations were considered separately. The role of such consultations should be further explored in other studies, which may provide more information about their effects and indicate potential changes in their objectives and uses.
With regard to the type of hormone therapy, the poor adherence among patients who used both TMX and AIS has been corroborated in others studies $[19,26]$. This finding might be due to the frequent musculoskeletal toxicity associated with AIS [30]. Other studies have found no statistically significant differences between the different types of hormone therapy and adherence [31,32], although a lower adherence rate has been noted for anastrozole than for TMX [32]. It is noteworthy that in the current study cohort, the majority $(64.4 \%)$ of the women were treated with TMX alone, while $29.8 \%$ received a combination of TMX and AIS and a few women (5.8\%) were treated only with AIS. The indication of each drug according to the patient's morbidity profile was not analyzed.

\section{Conclusion}

In this cohort, approximately $25 \%$ of the breast cancer patients were considered to be non-adherent to hormone treatment, thus risking a clinical response below the expected standards. Moreover, this study identified the patient characteristics that are associated with greater vulnerability while receiving hormone therapy for breast cancer and reveals the health care practices that facilitate adherence to treatment. Interventions based on these results may help improve patient adherence, quality of care and outcomes.

\section{Abbreviations \\ AIS: Aromatase inhibitors; CT: Chemotherapy; DTS: Diagnostic and therapeutic services; HT: Hormone therapy; INCA: National cancer institute; MPR: Medication possession ratio; MTS: Multi-professional therapeutic support; OR: Odds ratio; RHC: Hospital-based cancer registry; RT: Radiotherapy; SHI: Integrated hospital system; SUS: Unified health system; TMX: Tamoxifen.}

\section{Competing interests}

The authors declare that they have no competing interests.

\section{Authors' contributions}

All authors participated in study design, dataset preparation by combining the databases, statistical analysis, and drafting and/or reviewing the manuscript. All authors read and approved the final manuscript

\section{Author details}

${ }^{1}$ Department of Health Administration and Planning of National School of Public Health Sergio Arouca, Oswaldo Cruz Foundation, Av. Leopoldo Bulhões, 1480/ Sala 717 -Manguinhos, 21041-210 Rio de Janeiro, RJ, Brazil. ${ }^{2}$ National School of Statistical Sciences, Brazilian Institute of Geography and Statistics, Rio de Janeiro, RJ, Brazil.

Received: 24 May 2013 Accepted: 28 May 2014

Published: 3 June 2014

\section{References}

1. Ruddy K, Mayer E, Partridge A: Patient adherence and persistence with oral anticancer treatment. CA Cancer J Clin 2009, 59:56-66.

2. Vervoort MM, Draisma G, Fracheboud J, Van de Poll-Franse LV, Koning HJ: Trends in the usage of adjuvant systemic therapy for breast cancer in the Netherlands and its effect on mortality. Br J Cancer 2004, 91:242-247.

3. Early Breast Cancer Trialists' Collaborative Group (EBCTCG): Tamoxifen for early breast cancer: an over- view of the randomized trials. Lancet 1998, 351:1451-1467. 
4. Early Breast Cancer Trialists' Collaborative Group (EBCTCG): Effects of chemotherapy and hormonal therapy for early breast cancer on recurrence and 15-year survival: an overview of the randomised trials. Lancet 2005, 365:1687-1717.

5. Arimidex, Tamoxifen, Alone or in Combination (ATAC) Trialists' Group, Forbes JF, Cuzick J, Buzdar A, Howell A, Tobias JS, Baum M: Effect of anastrozole and tamoxifen as adjuvant treatment for early stage breast cancer: 100-month analysis of the ATAC trial. Lancet Oncol 2008, 9:45-53.

6. Breast International Group (BIG) 1-98 Collaborative Group, Thürlimann B, Keshaviah A, Coates AS, Mouridsen H, Mauriac L, Forbes JF, Paridaens R, Castiglione-Gertsch M, Gelber RD, Rabaglio M, Smith I, Wardley A, Price KN Goldhirsch A: A comparison of letrozole and tamoxifen in postmenopausal women with early breast cancer. N Engl J Med 2005, 353:2747-2757.

7. Ministério da Saúde (MS): Sistema de Informações Ambulatoriais do SUS (SIA/SUS). Manual de Bases Técnicas Oncologia. In Brasília/DF, novembro de 2008. disponível em [http://w3.datasus.gov.br/siasih/arquivos/ Manu_Onco_20-11-11.pdf]

8. WHO (World Health Organization): National Cancer Control Programmes: Policies and Managerial Guidelines. 2nd edition. Geneva: WHO; 2002.

9. Burstein HJ, Winer EP: Primary care for survivors of breast cancer. N Engl J Med 2000, 343:1086-1094.

10. Avorn J, Monette J, Lacour A, Bohn RL, Monane M, Mogun H, LeLorier J: Persistence of use of lipid-lowering medications: a cross-national study. JAMA 1998, 279:1458-1462.

11. Ministério da Saúde (MS)/ Instituto Nacional de Câncer: Estimativa 2012: Incidência de Câncer no Brasil. Rio de Janeiro: INCA/MS; 2011:2011.

12. McCowan C, Shearer J, Donnan PT, Dewar JA, Crilly M, Thompson AM, Fahey TP: Cohort study examining tamoxifen adherence and its relationship to mortality in women with breast cancer. Br J Cancer 2008, 99:1763-1768.

13. Pellegrini I, Sarradon-Eck A, Soussan PB, Lacour AC, Largillier R, Tallet A, Tarpin C, Julian-Reynier C: Women's perceptions and experience of adjuvant tamoxifen therapy account for their adherence: breast cancer patients' point of view. Psychooncology 2009, 19:472-479.

14. Partridge AH, LaFountain A, Mayer E, Taylor BS, Winer E, Asnis-Alibozek A: Adherence to initial adjuvant anastrozole therapy among women with early-stage breast cancer. JCO 2008, 26(4):556-562.

15. Hershman DL, Kushi LH, Shao T, Buono D, Kershenbaum A, Tsai WY Fehrenbacher L, Gomez SL, Miles S, Neugut Al: Early Discontinuation and Nonadherence to Adjuvant Hormonal Therapy in a Cohort of 8.769 Early-Stage Breast Cancer Patients. JCO 2010, 28(27):4120-4128.

16. Ministério da Saúde (MS): Portaria no 741, de 19 de dezembro de 2005 Definir as unidades de assistência de alta complexidade em oncologia, os centros de assistência de alta complexidade em oncologia (CACON) e os centros de referência de alta complexidade em oncologia e suas aptidões e qualidades. Diário Oficial União 2005, 246(1):113-124.

17. Cramer JA, Roy A, Burrell A, Fairchild CJ, Fuldeore MJ, Ollendorf DA, Wong PK Medication compliance and persistence: terminology and definitions. Value Health 2008, 11:44-47.

18. Peterson AM, Nau DP, Cramer JA, Benner J, Gwadry-Sridhar F, Nichol M, International Society for Pharmacoeconomics and Outcomes Research (ISPOR): A checklist for medication compliance and persistence studies using retrospective databases. Value Health 2007, 10(1):3-12

19. Murphy CC, Bartholomew LK, Carpentier MY, Bluethmann SM, Vernon SW: Adherence to adjuvant hormonal therapy among breast cancer survivors in clinical practice: a systematic review. Breast Cancer Res Treat 2012, 134:459-478.

20. Kimmick G, Anderson R, Camacho F, Bhosle M, Hwang W, Balkrishnan R: Adjuvant Hormonal Therapy Use Among Insured, Low-Income Women With Breast Cancer. J Clin Oncol 2009, 27:3445-3451.

21. Lin JH, Zhang SM, Manson JE: Predicting adherence to tamoxifen for breast cancer adjuvant therapy and prevention. Cancer Prev Res (Phila) 2011, 4:1360-1365.

22. Hershman DL, Shao T, Kushi LH, Buono D, Tsai WY, Fehrenbacher L, Kwan M, Gomez SL, Neugut Al: Early discontinuation and non-adherence to adjuvant hormonal therapy are associated with increased mortality in women with breast cancer. Breast Cancer Res Treat 2011, 126(2):529-537.

23. Barner JC: Medication Adherence: Focus on Secundary Database Analysis. In ISPOR Student Forum Presentation. 2010. Available in: http://www.ispor. org/student/teleconferences/ISPORStudentForumPresentation022410.pdf.
24. Guth U, Myrick ME, Schotzau A, Kilic N, Schmid SM: Drug switch because of treatment-related adverse side effects in endocrine adjuvant breast cancer therapy: how often and how often does it work? Breast Cancer Res Treat 2011, 129:799-807.

25. Güth U, Myrick ME, Kilic N, Eppenberger-Castori S, Schmid SM: Compliance and persistence of endocrine adjuvant breast cancer therapy. Breast Cancer Res Treat 2012, 131:491-499.

26. Wigertz A, Ahlgren J, Holmqvist M, Fornander T, Adolfsson J, Lindman $\mathrm{H}_{\text {, }}$ Bergkvist L, Lambe M: Adherence and discontinuation of adjuvant hormonal therapy in breast cancer patients: a population-based study. Breast Cancer Res Treat 2012, 133:367-373.

27. Brito C, Portela MC, Vasconcellos MTL: Sobrevida de mulheres tratadas por câncer de mama no estado do Rio de Janeiro. Rev Saude Publica 2009, 43:481-489.

28. Rao VS, Jameel JK, Mahapatra TK, McManus PL, Fox JN, Drew PJ: Surgery is associated with lower morbidity and longer survival in elderly breast cancer patients over 80. Breast J 2007, 13:368-373.

29. Kim R, Toge T: Multidisciplinary approach to cancer treatment: a model for breast cancer treatment at the M. D. Anderson Cancer Center. Int J Clin Oncol 2004, 9:356-363.

30. Henry NL, Azzouz F, Desta Z, Li L, Nguyen AT, Lemler S, Hayden J, Tarpinian K, Yakim E, Flockhart DA, Stearns V, Hayes DF, Storniolo AM: Predictors of aromatase inhibitor discontinuation as a result of treatment-emergent symptoms in early-stage breast cancer. J Clin Oncol 2012, 30:936-942.

31. Chlebowski RT, Geller ML: Adherence to Endocrine Therapy for Breast Cancer. Oncology 2006, 71:1-9.

32. Ziller V, Kalder M, Albert US, Holzhauer W, Ziller M, Wagner U, Hadji P: Adherence to adjuvant endocrine therapy in postmenopausal women with breast cancer. Ann Oncol 2009, 20:431-436

doi:10.1186/1471-2407-14-397

Cite this article as: Brito et al:: Adherence to hormone therapy among women with breast cancer. BMC Cancer 2014 14:397.

\section{Submit your next manuscript to BioMed Central and take full advantage of:}

- Convenient online submission

- Thorough peer review

- No space constraints or color figure charges

- Immediate publication on acceptance

- Inclusion in PubMed, CAS, Scopus and Google Scholar

- Research which is freely available for redistribution 